\title{
Optimal Slip Ratio Based Fuzzy Control of Acceleration Slip Regulation for Four-Wheel Independent Driving Electric Vehicles
}

\author{
Guodong Yin, ${ }^{1,2}$ Shanbao Wang, ${ }^{1}$ and Xianjian Jin ${ }^{1}$ \\ ${ }^{1}$ School of Mechanical Engineering, Southeast University, Nanjing 211189, China \\ ${ }^{2}$ State Key Laboratory of Mechanical Transmission, Chongqing University, Chongqing 400044, China \\ Correspondence should be addressed to Guodong Yin; ygd@seu.edu.cn
}

Received 26 September 2013; Accepted 27 October 2013

Academic Editor: Hui Zhang

Copyright ( $\odot 2013$ Guodong Yin et al. This is an open access article distributed under the Creative Commons Attribution License, which permits unrestricted use, distribution, and reproduction in any medium, provided the original work is properly cited.

To improve the driving performance and the stability of the electric vehicle, a novel acceleration slip regulation (ASR) algorithm based on fuzzy logic control strategy is proposed for four-wheel independent driving (4WID) electric vehicles. In the algorithm, angular acceleration and slip rate based fuzzy controller of acceleration slip regulation are designed to maintain the wheel slip within the optimal range by adjusting the motor torque dynamically. In order to evaluate the performance of the algorithm, the models of the main components related to the ASR of the four-wheel independent driving electric vehicle are built in MATLAB/SIMULINK. The simulations show that the driving stability and the safety of the electric vehicle are improved for fuzzy logic control compared with the conventional PID control.

\section{Introduction}

The demand for more environmentally friendly and fuel efficient vehicles has been increased in response to growing concerns about a clean environment and saving energy. Pure electric vehicle stands out with its superior zero emission performance; it has emerged as a viable solution to meet those requirements [1,2]. Therefore, the research on electric vehicle is important.

A 4WID electric vehicle employs four in-wheel (or hub) motors to drive the four wheels, and the torque and driving mode of each wheel can be controlled independently. As one of the most popular active safety systems of vehicles, acceleration slip regulation (ASR) is widely used in 4WID electric vehicles nowadays to improve the vehicle's acceleration performance [3-6]. The basic principle of ASR is to control the slip rate of driving wheels within the range of the optimal slip rate. The research on ASR is conducted using the sliding mode variable structure control system, the PID control, and the optimal control separately [7-11]. Based on the threshold angular acceleration and adhesion rate, an antiskid fuzzy logic controller was designed, and the simulation results show that the fuzzy controller can effectively keep the slip rate in a reasonable range [12-15].

In this paper, a fuzzy logic control strategy of acceleration slip regulation based on angular acceleration and slip rate is proposed to maintain the wheel slip within the optimal range by adjusting the motor torque dynamically. The simulation results show that the fuzzy controller effectively prevents driving wheel slipping and reduces the slip rate.

\section{Vehicle Dynamic Model}

A quarter dynamics vehicle model is established as follows.

2.1. The Wheel Dynamic Model. The dynamic differential equations for the calculation of longitudinal motion of the vehicle are described as follows [16]:

$$
\begin{gathered}
m \dot{u}=F_{d}-F_{f} \\
j_{\omega} \dot{\omega}_{i}=T_{i}-F_{d} R+F_{z i} f R \\
F_{d}=\mu_{i}(\lambda) F_{z i} .
\end{gathered}
$$


Considering the longitudinal acceleration and lateral acceleration of the vehicle, the normal load expression for each wheel could be written as

$$
\begin{aligned}
& F_{z(f l, f r)}=\left(\frac{1}{2} M g \pm M a_{y} \frac{h}{d_{f}}\right) \frac{l_{r}}{l}-\frac{1}{2} M a_{x} \frac{h}{l} \\
& F_{z(r l, r r)}=\left(\frac{1}{2} M g \pm M a_{y} \frac{h}{d_{r}}\right) \frac{l_{f}}{l}+\frac{1}{2} M a_{x} \frac{h}{l},
\end{aligned}
$$

where $i$ is $f l, f r, r l, r r ; M, m, u$ are the vehicle mass, a quarter of the mass vehicle, and vehicle velocity, respectively, $F_{f}$ is the driving resistance; $F_{d}$ is the driving force; $j_{\omega}$ is the wheel inertia; $\omega_{i}$ is the wheel rotational speed of $i$ th wheel; $T_{i}$ is the driving torque of $i$ th in-wheel motor; $f, \mu_{i}, F_{z i}$ are the coefficient of rolling friction, friction coefficient of $i$ th wheel, and normal force of $i$ th tire, respectively (Figure 1).

\subsection{Slip Ratio.}

$$
\begin{aligned}
& \lambda_{i}=\frac{R \omega_{i}-u_{i}}{R \omega_{i}} \quad \text { (driving) } \\
& \lambda_{i}=\frac{u_{i}-R \omega_{i}}{u_{i}} \quad \text { (braking), }
\end{aligned}
$$

where $\lambda_{i}$ is the lip ratio of $i$ th tire and $u_{i}$ is the center speed of $i$ th wheel.

2.3. Model of In-Wheel Motor. In this paper, the mathematical model of permanent magnet synchronous in-wheel motor can be expressed as follows:

$$
\begin{aligned}
& u_{d}=r i_{d}+\frac{d \psi_{d}}{d t}-\omega_{s} \psi_{q}, \\
& u_{q}=r i_{q}+\frac{d \psi_{q}}{d t}+\omega_{s} \psi_{d},
\end{aligned}
$$

where $\psi_{d}=L_{d} i_{d}+M_{a f d} i_{f}, \psi_{q}=L_{q} i_{q}, \omega_{s}=p \omega_{r} ; u_{d}, u_{q}$ are $d$ - and $q$-axis stator voltages, respectively; $i_{d}, i_{q}$ are $d$ and $q$-axis stator currents, respectively; $\psi_{d}, \psi_{q}$ are d- and qaxis flux linkage, respectively; $L_{q}, L_{d}$ are $d$ - and $q$-axis stator inductances respectively; $r$ is stator resistance.

Meanwhile, motor torque equation is defined as

$$
T_{e}=\frac{3}{2} p\left[\psi_{f d} i_{q}+\left(L_{d}-L_{q}\right) i_{d} i_{q}\right]
$$

Motion equation:

$$
\frac{d \omega_{r}}{d t}=\frac{1}{J}\left[T_{e}-B \omega_{r}-T_{l}\right]
$$

where $B$ is damping coefficient, $J$ is rotational inertia, $T_{l}$ is load torque, and $p$ is number of pole pairs.

We take $i_{q}, \omega_{r}$ as state variables with motor control, $i_{d}=0$. The state equations of permanent magnet synchronous motor (PMSM) can be represented as follows:

$$
\left[\begin{array}{c}
\dot{x}_{1} \\
\dot{x}_{2}
\end{array}\right]=\left[\begin{array}{cc}
\frac{-r}{L_{q}} & \frac{-p \psi_{f d}}{L_{q}} \\
\frac{3}{2 J} p \psi_{f d} & \frac{-B}{J}
\end{array}\right]\left[\begin{array}{l}
x_{1} \\
x_{2}
\end{array}\right]+\left[\begin{array}{cc}
\frac{1}{L_{q}} & 0 \\
0 & \frac{-1}{J}
\end{array}\right]\left[\begin{array}{c}
u \\
T_{l}
\end{array}\right] .
$$

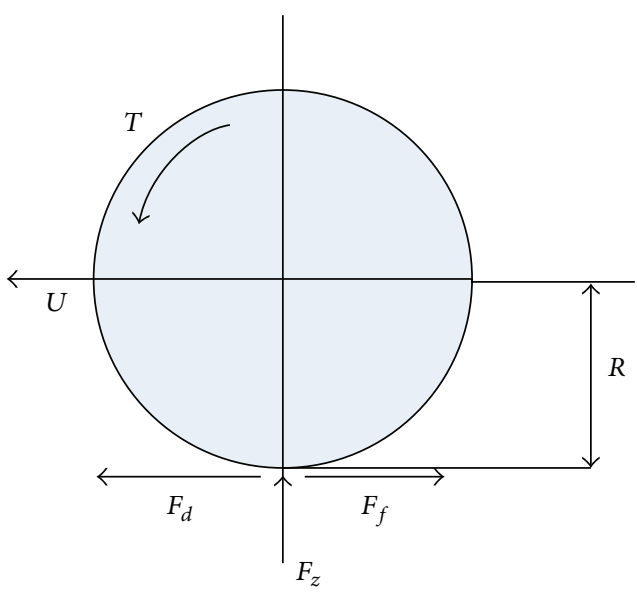

FIgURE 1: A quarter vehicle dynamic model.

The control input variables are $u$ and $T_{l}$, and the output variables are $i_{q}$ and $\omega_{r}$.

\section{Control Algorithm of ASR}

It is easy to lead wheel excessive slip for the driving of fourwheel drive electric vehicle on the low adherent surfaces, and the excessive slip of wheel affects the stability and safety of vehicle. Wheel angular acceleration increases rapidly in the process of excessive slip, which cause slip ratio to increase quickly and driving force to decrease. In this paper, a fuzzy controller of acceleration slip regulation based on angular acceleration and slip rate is designed, and the wheel slip rate will be controlled in a reasonable range.

3.1. Threshold Angular Acceleration. Ignoring the rolling resistance and wind resistance, the relationship between wheel angular acceleration $\alpha$, torque $T_{i}$, and slip ratio $\lambda$ can be described by as the following formulas:

$$
\begin{aligned}
& \dot{\lambda}=\frac{-\dot{u} \omega R+\dot{\omega} u R}{\omega^{2} R^{2}}=\frac{\left[j_{\omega}+(1-\lambda) m R^{2}\right] \alpha-T_{i}}{\omega m R^{2}}, \\
& \alpha=\dot{\omega}=\frac{T_{i}}{j_{\omega}+m R^{2}(1-\lambda)}+\frac{\omega m R^{2} \dot{\lambda}}{j_{\omega}+m R^{2}(1-\lambda)}
\end{aligned}
$$

If slip rate $\lambda$ increases slowly, $\dot{\lambda} \approx 0$. Wheel angular acceleration can be represented as follows:

$$
\alpha=\frac{T_{i}}{j_{\omega}+m R^{2}(1-\lambda)} .
$$

With the increase of slip rate, angular acceleration is always greater than this value in fact. During the process of control, angular acceleration only needs to be close to this value. According to the automobile theory, when the wheel goes into slip state during driving, wheel angular acceleration and slip ratio will increase rapidly. Therefore the angular acceleration reflects whether the vehicle is in a state of slip to some extent. 


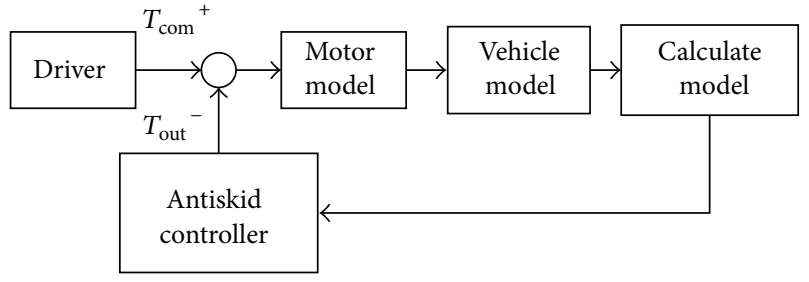

FIGURE 2: The block diagram of ASR control.

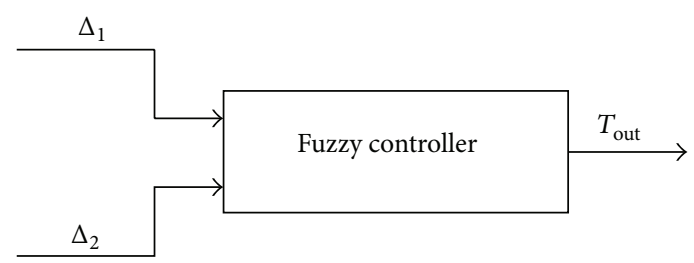

FIgURE 3: The block diagram of fuzzy controller.

TABLE 1: Fuzzy rules.

\begin{tabular}{lccccccc}
\hline \multirow{2}{*}{$T_{\text {out }}$} & \multicolumn{7}{c}{$\Delta_{1}=\alpha-\alpha_{p}$} \\
& NB & NM & NS & ZO & PS & PM & PB \\
\hline$\Delta_{2}=\lambda-\lambda_{\text {opt }}$ & & & & & & & \\
NS & ZO & ZO & ZO & ZO & ZO & ZO & ZO \\
ZO & ZO & ZO & ZO & ZO & ZO & PS & PS \\
PS & ZO & ZO & ZO & ZO & PS & PM & PM \\
PM & ZO & ZO & PS & PS & PM & PB & PB \\
PB & ZO & PS & PM & PM & PB & PB & PB \\
\hline
\end{tabular}

The control aim for ASR is to make slip ratio near optimal slip ratio and to obtain high driving force. The angular acceleration threshold value can be described as follows:

$$
\alpha_{p}=\frac{T_{i}}{j_{\omega}+m R^{2}\left(1-\lambda_{\mathrm{opt}}\right)} .
$$

3.2. The Optimal Slip Ratio. In this paper, two optimal slip ratios are considered. The optimal slip ratios of front wheel and rear wheel are 0.2 and 0.16 , respectively.

3.3. The Antiskid Control Structure of 4WID EV. The electric vehicle rapidly accelerates under the instruction of drivers, and antiskid controller properly regulates four torques of the motor according to the current motion state of vehicle to maintain the slip rate of wheel in a reasonable range.

As shown in Figure 2, the electric vehicle generates torque $T_{\text {com }}$ according to driver's instructions. Antiskid controller generates $T_{\text {out }}$ according to the current state of vehicle. The command torque of the motor is the difference between the $T_{\text {com }}$ and $T_{\text {out }}$.

\section{Antiskid Controller}

It is clear that the increasing slip ratio can increase the driving force between the road and the tire by virtue of an increase

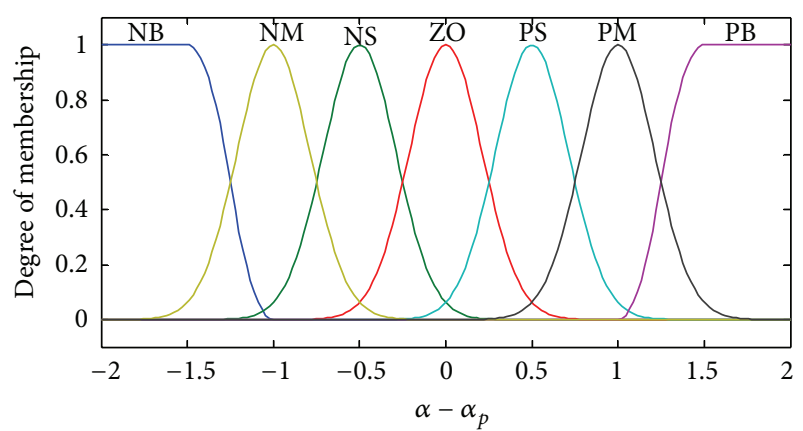

FIGURE 4: Difference between actual angular acceleration and threshold angular acceleration; $\Delta_{1}=\alpha-\alpha_{p}$.

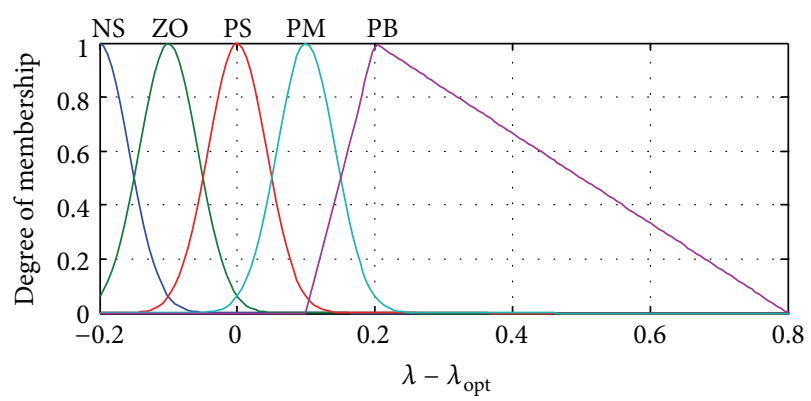

FIgURE 5: Difference between actual slip and optimal slip, $\Delta_{2}=\lambda-$ $\lambda_{\text {opt }}$.

of friction coefficient, but further increase of slip will reduce driving force and induce an unstable acceleration of the wheel. Therefore, if the slip ratio is bigger than the optimal slip ratio $\lambda_{\text {opt }}$, the driving force will be diminished drastically. An antiskid controller is designed to maintain the wheel slip within the optimal range by adjusting the motor torque dynamically.

4.1. Fuzzy Antiskid Controller. In this paper, a fuzzy antiskid controller is designed according to the principle of fuzzy control. The fuzzy controller has two input signals, and two inputs are the difference between actual slip ratio and threshold slip ratio and the difference between actual angular acceleration and threshold angular acceleration. Fuzzy antiskid controller block diagram is described as in Figure 3.

The input signals are shown in Figure $3 ; \Delta_{1}=\alpha-\alpha_{p}$ and $\Delta_{2}=\lambda-\lambda_{\text {opt }}$. The controller generates one output $T_{\text {out }}$ according to the input current value and the fuzzy rules. The value can reduce torque of the motor and thus reduce the driving wheel slip rate.

According to the theoretical derivation and practical experience, membership functions of inputs and output are shown in Figures 4, 5, and 6. The $\Delta_{1}$ and the $T_{\text {out }}$ are divided into seven fuzzy subsets: [NB, NM, NS, ZO, PS,PM, PB], and the $\Delta_{2}$ is divided into five fuzzy subsets: [NS, ZO, PS, PM, $\mathrm{PB}]$.

The Mamdani methods and gravity center method are used to perform the fuzzy logic calculation and defuzzy identification in this paper. Table 1 shows the rule base for the fuzzy antiskid controller. 


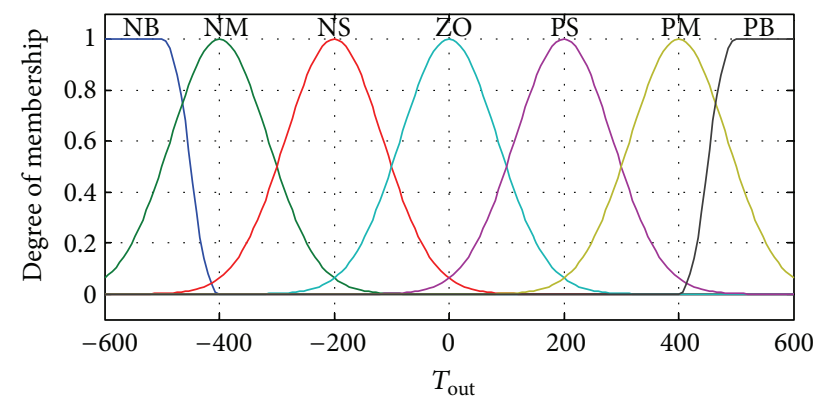

Figure 6: The output of fuzzy controller, $T_{\text {out }}$.

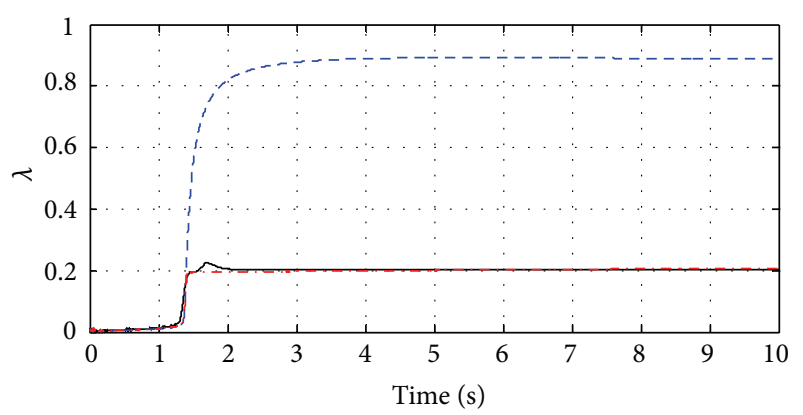

- PID control
- - - Without control
-.. Fuzzy control

FIGURE 7: The slip of front wheel.

The output of fuzzy antiskid controller is determined by considering the difference between actual slip ratio and optimal slip ratio and the difference between actual angular acceleration and threshold angular acceleration. If the actual angular acceleration is less than the threshold angular acceleration, it shows that driving wheel adhesion is in a good condition. Meanwhile, if the output variable of controller is zero, the fuzzy controller does not reduce the torque out of drive motor. If the actual angular acceleration is larger than the threshold angular acceleration, it shows that the drive wheel is in a state of slip. Fuzzy controller decides the output variable according to the current value of slip ratio. The output variable of fuzzy controller can reduce output torque of motor and reduce the slip rate of drive wheel.

4.2. PID Controller. In this paper, a PID antiskid controller is designed to compare the effect of fuzzy controller and PID controller. The main design intent for this antiskid controller is to maintain actual slip near a reference value. The input of PID controller is the error of signal $\Delta \lambda=\lambda-\lambda_{\text {opt }}$, and the output can be represented as follows:

$$
T_{\text {outpid }}(t)=K_{p} \Delta \lambda(t)+K_{i} \int \Delta \lambda(t) d t+K_{d} \frac{d \Delta \lambda(t)}{d t},
$$

where $K_{p}, K_{i}$, and $K_{d}$ are the proportional gains, the integral coefficient, and the differential coefficient, respectively.

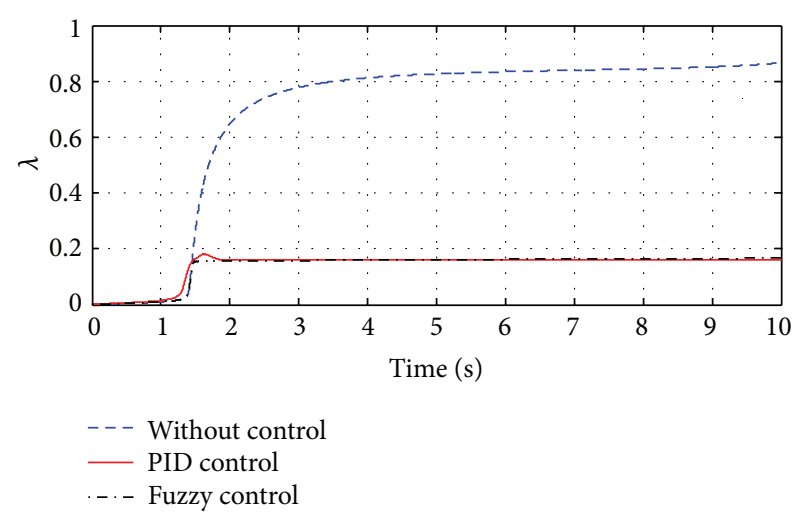

FIgURE 8: The slip of rear wheel.

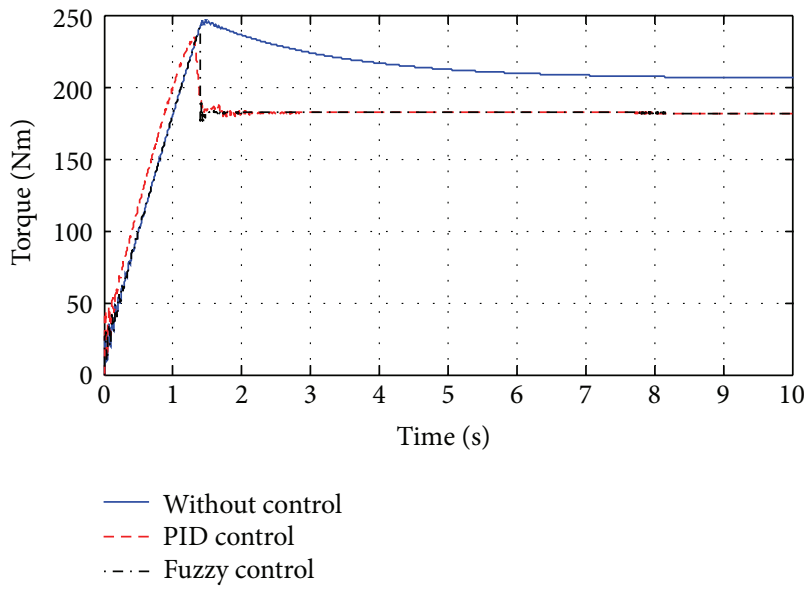

Figure 9: The motor torque of front wheel.

\section{Simulation Results and Analysis}

The simulation platform is built in MATLAB/SIMULINK and CarSim to evaluate the performance of the proposed antiskid controller. The 4WID full-vehicle dynamics model is established in CarSim including front and rear suspension, steering, body tires, and other systems. The antiskid controller and motor model are established in MATLAB/SIMULINK. Two kinds of road surface conditions are established to observe the effect of the fuzzy controller and PID controller.

5.1. The First Test Condition. The electric vehicle rapidly accelerates at an initial speed of $5 \mathrm{~km} / \mathrm{h}$. In this simulation the tire-road friction coefficient (TRFC) is set to 0.2. The acceleration command from driver is so large that the vehicle begins to slip on the low adhesion road. The simulation results are shown as in Figures 7 and 8.

The slip ratios of front wheel and rear wheel are shown in Figure 7 and Figure 8. The vehicle runs on the low friction coefficient road. The slip rate of front wheel reaches 0.9 quickly without antiskid controller. Under effect of the fuzzy antiskid controller, the slip rate of front wheel and rear wheel are close to optimal slip ratio 0.2 and 0.16 , respectively. Both 


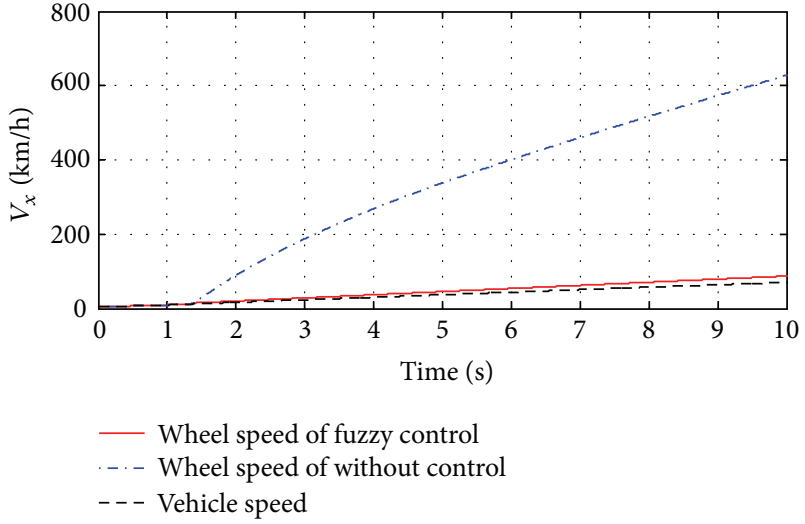

FIGURE 10: Comparison of speed for front wheel.

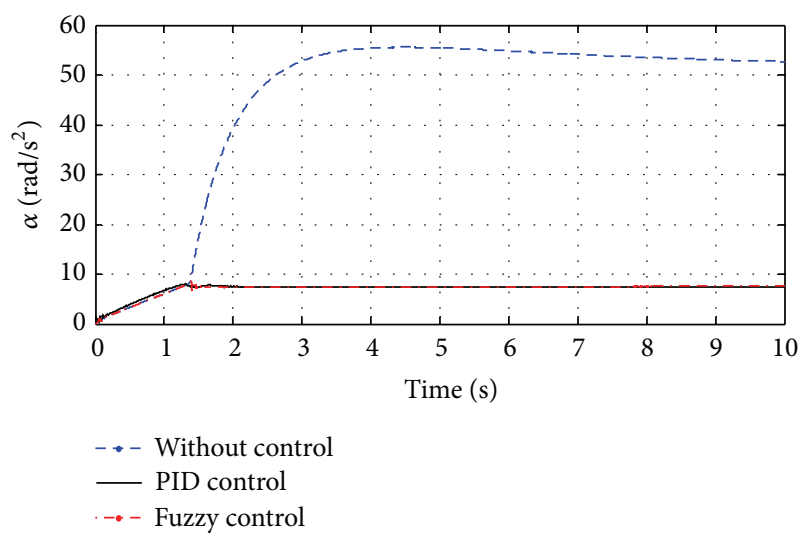

Figure 11: The actual angular acceleration for front wheel.

of fuzzy controller and PID controllers can reduce the slip and improve the stability of the electric vehicle. However, the control performance of the proposed fuzzy controller is better than that of the conventional PID controller.

As shown in Figure 9, both of fuzzy controller and PID controller can reduce motor torque of front wheel. Finally, the motor torques are the same in different control methods. In addition, the wheel angular velocity is shown in Figure 10, and the fuzzy antiskid controller can effectively reduce the wheel angular velocity.

As shown in Figure 11, both of fuzzy controller and PID controller can reduce actual angular acceleration for front wheel.

As shown in Figure 12, the difference between actual angular acceleration and threshold angular acceleration raises rapidly without antiskid controller. Under the effect of fuzzy antiskid controller, the difference between actual angular acceleration and threshold angular acceleration is close to zero. The threshold angular acceleration is effective to reduce actual angular acceleration.

As shown in Figure 13, The difference between actual slip ratio and threshold slip ratio reaches 0.7 rapidly without antiskid controller. Under the effect of fuzzy antiskid controller, the actual slip ratio is close to optimal slip.

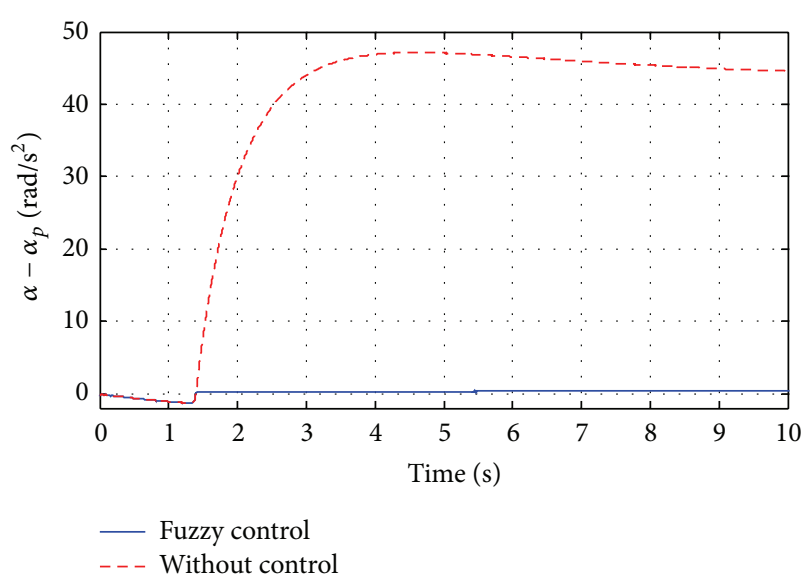

FIGURE 12: Difference between actual angular acceleration and threshold angular acceleration.

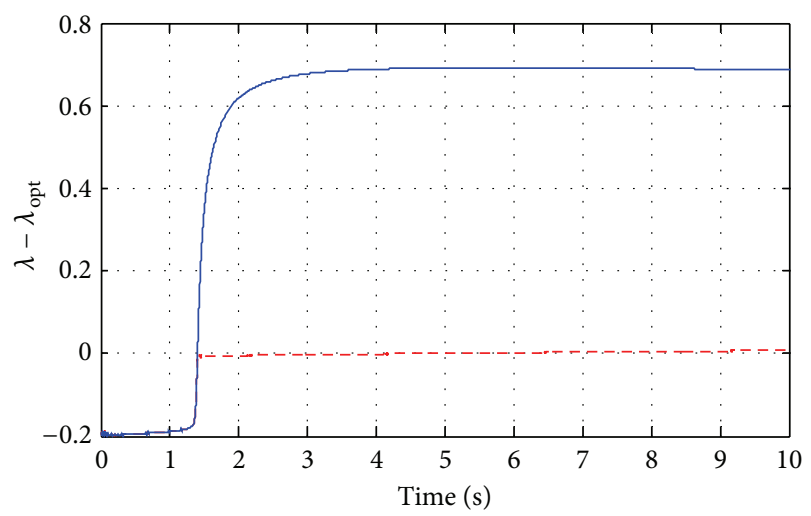

- - - Fuzzy control

— Without control

FIGURE 13: Difference between actual slip ratio and optimal slip ratio.

5.2. The Second Test Condition. The electric vehicle rapidly accelerates at an initial speed of $20 \mathrm{~km} / \mathrm{h}$. The steering angle of front wheel is 5 degree. In this simulation the TRFC was set to 0.2 . The acceleration command from driver is so large that the vehicle begins to slip on the low adhesion road. The simulation results are shown in Figure 14.

As shown in Figure 14, The slip rate of front wheel reaches 0.85 quickly without antiskid controller. Under effect of the antiskid controller, the slip rate of front wheel is close to optimal slip ratio 0.2 .

The lateral acceleration of vehicle is shown in Figure 15. It can be seen from the figure that the lateral acceleration of vehicle under the effect of antiskid controller is bigger than that of lacking antiskid controller before 8 second. The vehicle begins to spin after 8 second, so the lateral acceleration of without controller is bigger than that of using controller. Both the fuzzy antiskid controller and PID antiskid controllers can enhance the lateral stability and safety of electric vehicle.

As shown in Figure 16, with the effect of fuzzy antiskid controller, the difference between actual angular acceleration and threshold angular acceleration is close to zero. The fuzzy 


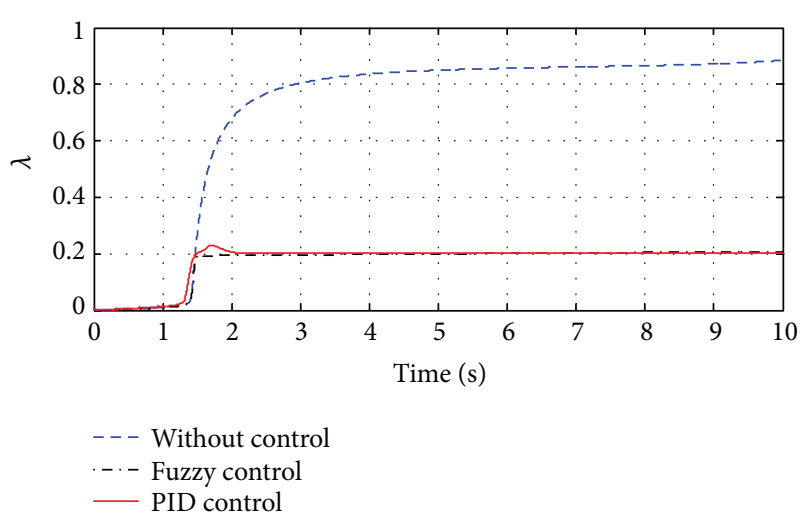

FIgURE 14: The slip of front wheel.

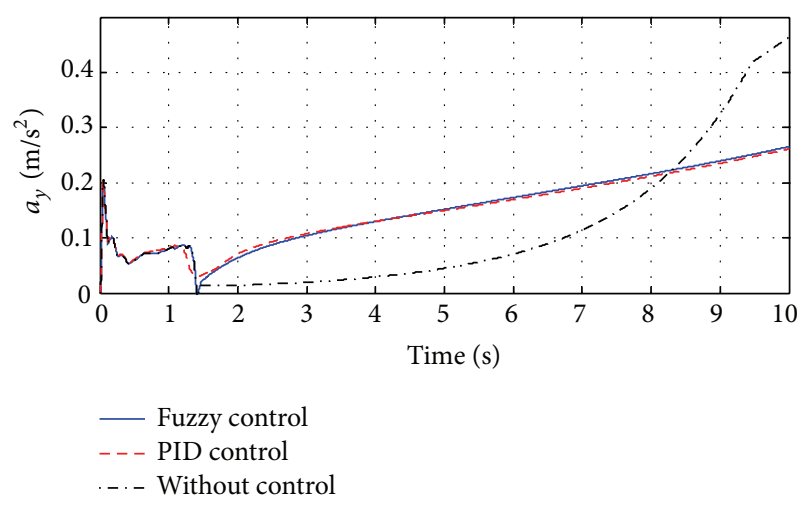

FIGURE 15: The lateral acceleration of vehicle.

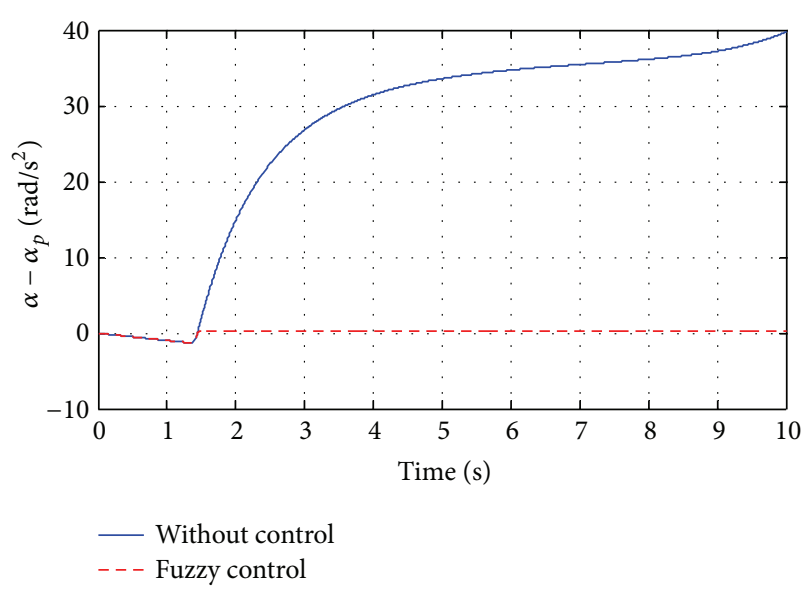

FIGURE 16: Difference between actual angular acceleration and threshold angular acceleration.

antiskid controller is effective to reduce actual angular acceleration.

The yaw rate of vehicle is shown in Figure 17. Under the effect of fuzzy controller, the yaw rate of vehicle maintains steadiness at $0.018 \mathrm{rad} / \mathrm{s}$ while the yaw rate of vehicle without fuzzy controller raises quickly. Figure 17 shows that fuzzy antiskid controller can improve lateral stability of electric vehicle to a certain degree on ice road.

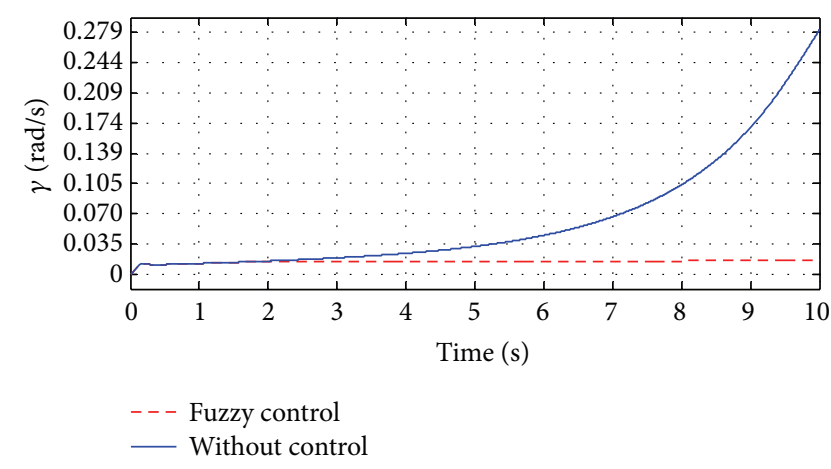

FIgURE 17: The yaw rate of vehicle.

\section{Conclusions}

In the paper, the antiskid fuzzy logic controller for fourwheel independent driving electric vehicles is proposed based on threshold angular acceleration and optimal slip rate. The simulation results show that fuzzy slip rate controller can effectively reduce the slip ratio. It can enhance the driving performance, the maneuverability, and stability of four-wheel independent driving electric vehicle.

\section{Acknowledgments}

This research was supported by the National Science Foundation of China $(51105074,51205058)$ and the Foundation of State Key Laboratory of Mechanical Transmission (SKLMTKFKT-201206).

\section{References}

[1] L. Keqiang, "Automotive technology development trends and countermeasures of China," Automotive Engineering, vol. 31, no. 11, pp. 1005-1016, 2009.

[2] G. Chunlin, Z. Zijian, W. Li et al., "Prospects and key factors analysis of electric vehicles development," Automotive Engineering, vol. 34, no. 9, pp. 852-858, 2012.

[3] G. Yin, N. Chen, and P. Li, "Improving handling stability performance of four-wheel steering vehicle via $\mu$-synthesis robust control," IEEE Transactions on Vehicular Technology, vol. 56, no. 5, pp. 2432-2439, 2007.

[4] Z. Shuai, H. Zhang, J. Wang, J. Li, and M. Ouyang, "Combined AFS and DYC control of four-wheel-independent-drive electric vehicles over can network with time-varying delays," IEEE Transactions on Vehicular Technology, 2013.

[5] L. Gang, Z. Changfu, Z. Qiang et al., "Acceleration slip regulation control of 4WID electric vehicles based on fuzzy road identification," Journal of South China University of Technology, vol. 40, no. 12, pp. 99-104, 2012.

[6] J. Deur, D. Pavković, G. Burgio, and D. Hrovat, "A model-based traction control strategy non-reliant on wheel slip information," Vehicle System Dynamics, vol. 49, no. 8, pp. 1245-1265, 2011.

[7] D. Yin, S. Oh, and Y. Hori, "A novel traction control for EV based on maximum transmissible torque estimation," IEEE Transactions on Industrial Electronics, vol. 56, no. 6, pp. 20862094, 2009. 
[8] M. Yoshimura and H. Fujimoto, "Driving torque control method for electric vehicle with in-wheel motors," IEEJ Transactions on Industry Applications, vol. 131, no. 5, pp. 721-728, 2011.

[9] H. Zhang, Y. Shi, and J. Wang, "Observer-based tracking controller design for networked predictive control systems with uncertain Markov delays," International Journal of Control, vol. 86, no. 10, pp. 1824-1836, 2013.

[10] R. De Castro, R. Esteves Araújo, and D. Freitas, "Wheel slip control of EVS based on sliding mode technique with conditional integrators," IEEE Transactions on Industrial Electronics, vol. 60, no. 8, pp. 3256-3271, 2013.

[11] H. Zhang, Y. Shi, and A. Saadat Mehr, "Robust static output feedback control and remote PID design for networked motor systems," IEEE Transactions on Industrial Electronics, vol. 58, no. 12, pp. 5396-5405, 2011.

[12] D. Zhiqiang, Fuzzy control of acceleration slip regulation for electric vehicles with in-wheel motors [M.S. thesis], Tongji University, Shanghai, China, 2006.

[13] H. Zhang, Y. Shi, and M. Liu, " $H_{\infty}$ step tracking control for networked discrete-time nonlinear systems with integral and predictive actions," IEEE Transactions on Industrial Informatics, vol. 9, no. 1, pp. 337-345, 2013.

[14] Y. Jiantao, Adhesion control method based on nonlinear control for four-wheel drive electric vehicle [M.S. thesis], Tongji University, Shanghai, China, 2008.

[15] H. Zhang, Y. Shi, and A. Saadat Mehr, "On $H_{\infty}$ filtering for discrete-time takagi-sugeno fuzzy systems," IEEE Transactions on Fuzzy Systems, vol. 20, no. 2, pp. 396-401, 2012.

[16] N. Zhao and B.-M. Ge, " $H_{\infty}$ robust control of permanent magnet synchronous motor used in electric vehicle," Electric Machines and Control, vol. 11, no. 5, pp. 462-466, 2007. 


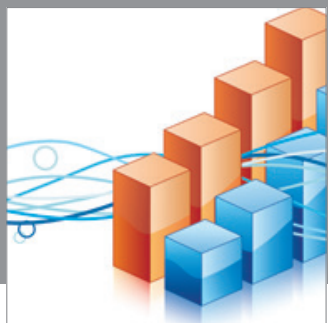

Advances in

Operations Research

mansans

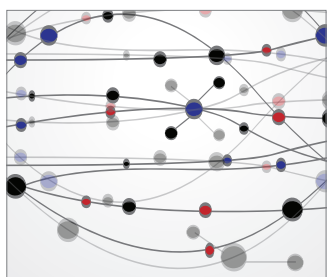

The Scientific World Journal
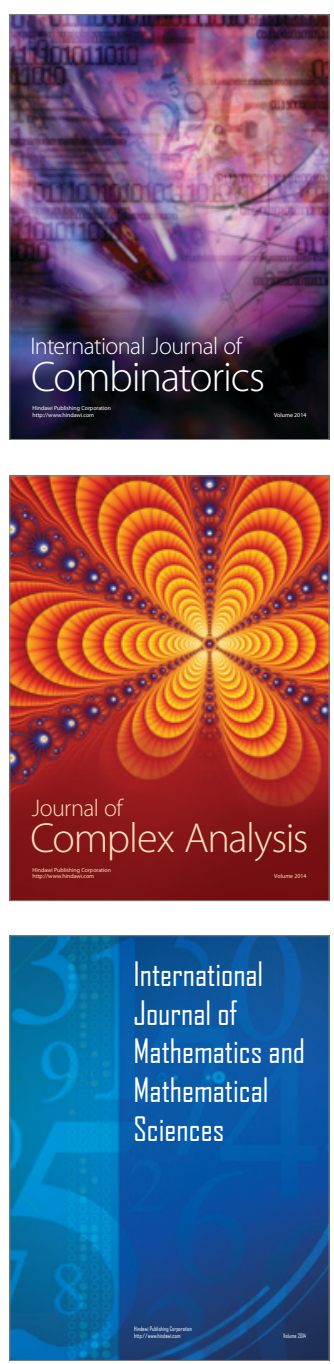
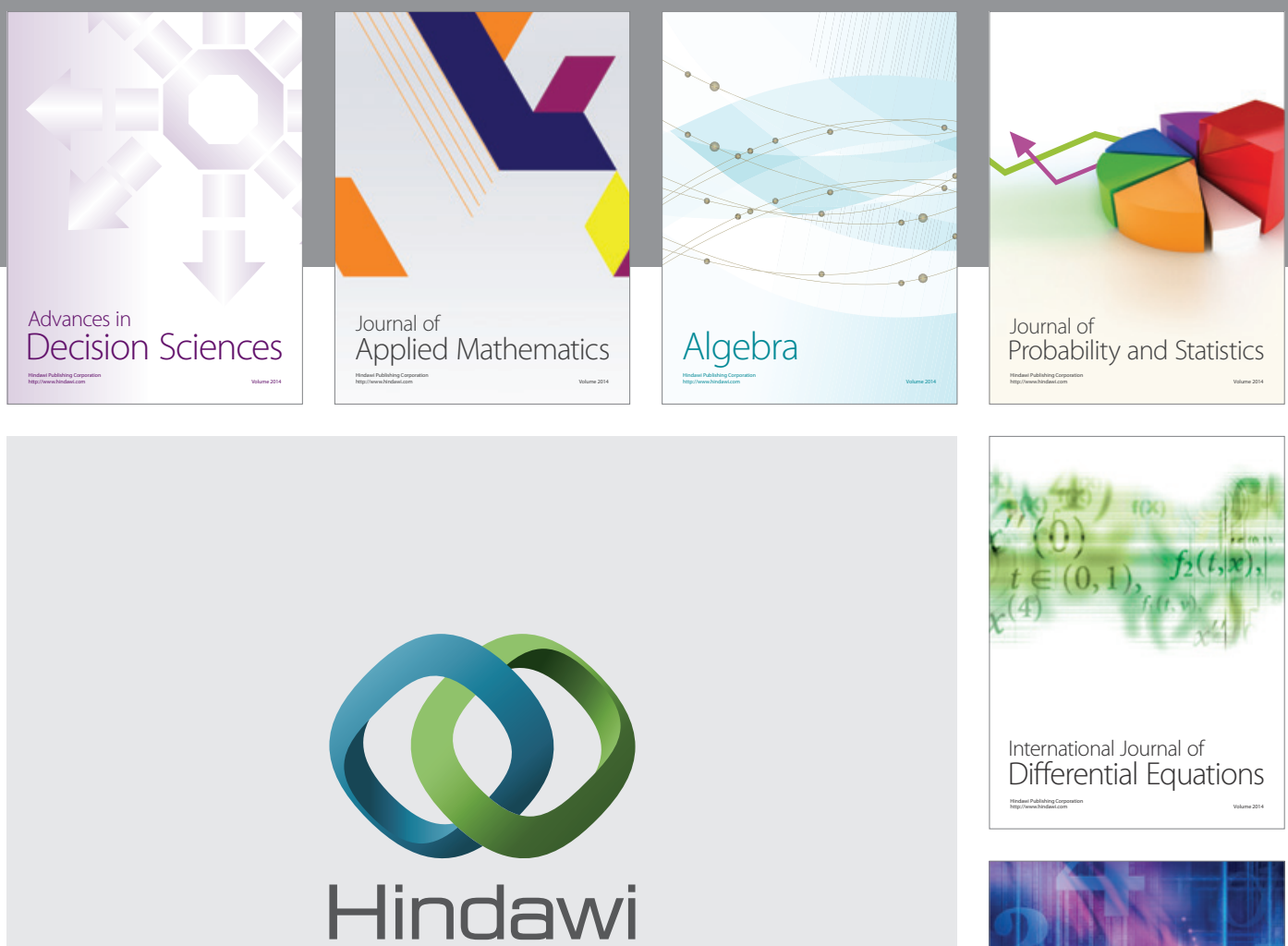

Submit your manuscripts at http://www.hindawi.com
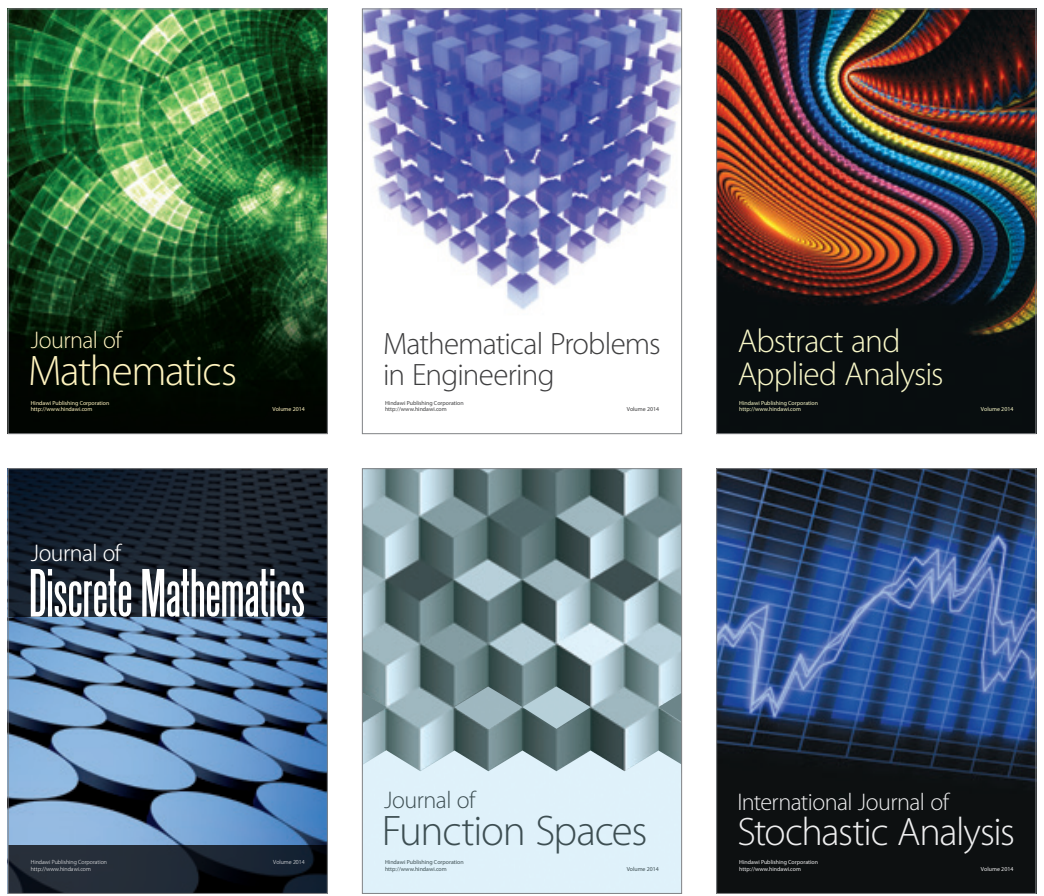

Journal of

Function Spaces

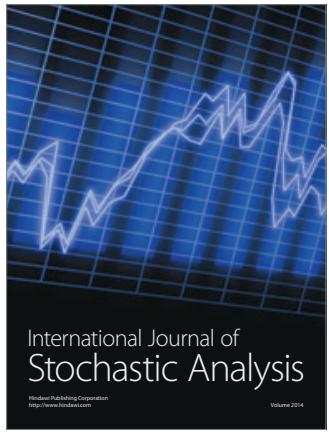

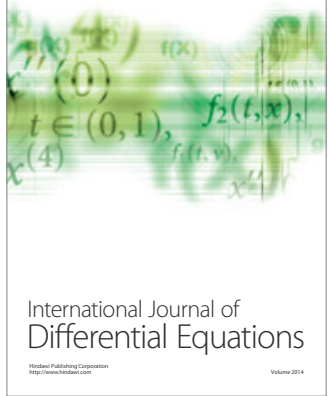
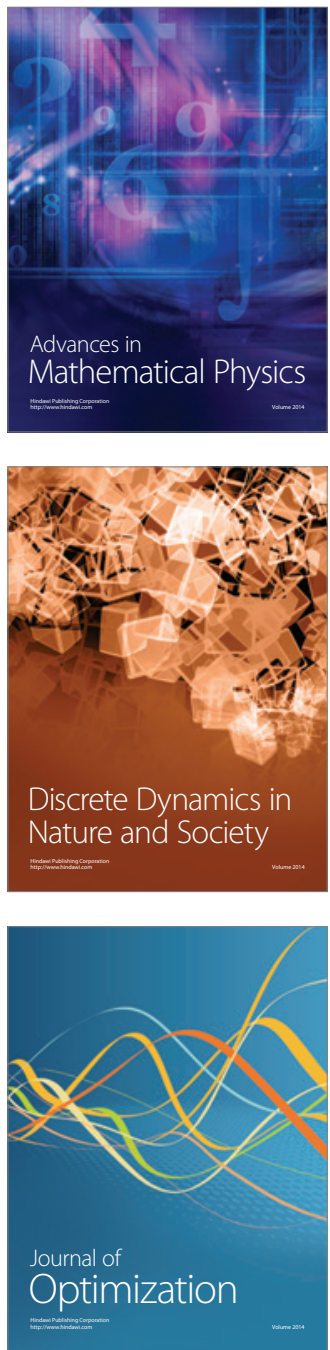